\title{
Reducing noise in the academic library: The effectiveness of installing noise meters
}

\section{Abstract}

Purpose: The objective of this research was to explore the effect of an electronic noise-monitoring device (NoiseSign) on reducing noise levels in quiet study areas in an academic library.

Design/methodology/approach: Surveys and decibel level measurements were used to measure the perceived and objective noise levels respectively, before and after the installation of the NoiseSign in both an intervention and a control area of two major branch libraries. Patrons' perception of noise was measured with a passive paper survey and online survey, which asked patrons to rate the current noise level and their desired noise level. The actual noise measurements were collected twice a day for sixty-second periods with a hand-held decibel reader and then corroborated after the intervention with automatically logged decibel readings from the noise monitor device in the two intervention areas. The authors conducted one-way ANOVAs to determine if the results were significant.

Findings: The NoiseSign had no statistically significant effect on either actual noise levels or user perceptions of noise in the library. Survey comments and anecdotal observation of the spaces while doing measurements did reveal that noise in the quiet study areas was not the primary source of complaints.

Originality/value: In spite of many proposed solutions to reducing noise in libraries, there has been very little research in this area. This is the first study to examine the effectiveness of using a noise-monitoring device in reducing noise levels in an academic library.

Keywords: Noise, quiet study, library spaces, noise reduction

\section{Introduction}

Noise in libraries is a constant source of concern for library users and administrators. This survey reports on the installation of a noise-monitoring sign at McGill University, a large university located in Montreal, Canada. Comments received from LibQUAL as well as from additional user surveys demonstrated that noise was a problem for McGill University Library in its individual study spaces. The matter of noise in the library became particularly pressing when a recent survey at our institution revealed that our users' primary purpose in using the library was individual study. McGill University Library had already employed noise-reduction strategies such as designating official quiet zones and purchasing appropriate quiet study furniture, such as carrels; however, it was clear from user comments that these changes were not sufficient.

Literature suggests that students adhere more to quiet policies when there is an authority figure or a monitoring presence in the area (Bedwell and Banks, 2013; Bird and Puglisi, 1984). The monitoring figure need not necessarily be a staff member; in their article on library design, Foster and Gibbons (2007) found that students "taught" each other the sometimes implicit rules about the spaces they were in "through an occasional verbal warning" or "gave them 'the stare' or glare that 
communicates 'be quiet!'. However, given budgetary concerns and current staffing levels, McGill University Library could not request staff to patrol quiet areas nor hire security guards in that capacity. Also, relying on student selfmonitoring would be unreliable. In the absence of a human monitoring figure, it was posited that an electronic noise-monitoring device (NoiseSign) would have the same effect.

NoiseSign (Figure 1) is a wall-mounted device that lights up to provide immediate visual feedback when the noise level in a designated area gets too loud. Although no literature currently exists on the NoiseSign or similar devices in libraries, there is research related to visual feedback devices and speeding in transportation literature. This research indicates that drivers reduce their speed in the presence of speed feedback signs (Bloch, 1998; Gehlert et al., 2012; SantiagoChaparo et al., 2012). Both the NoiseSign and speed feedback signs provide immediate visual information with regards to "negative" behaviour. As demonstrated in transportation literature, drivers modify their behaviour by reducing their driving speed. Thus we hypothesized that the NoiseSign would provide the feedback necessary for patrons to modify their behaviour and reduce noise-making

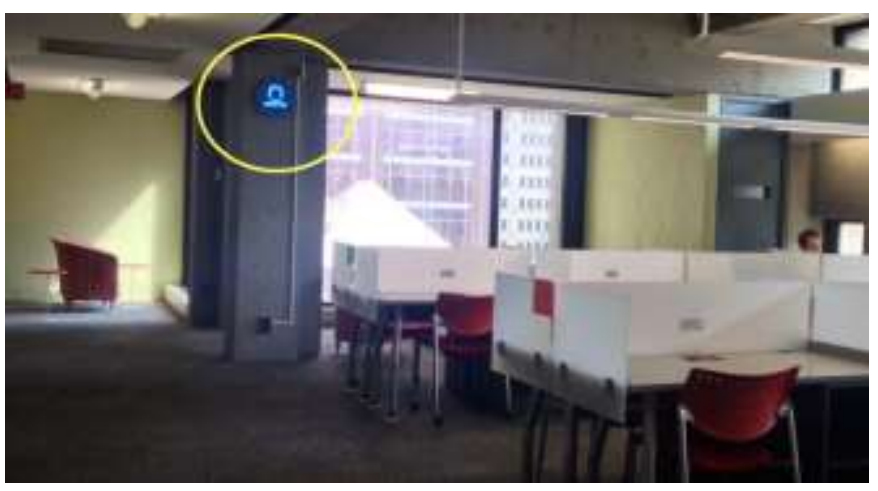

Figure 1: NoiseSign installed in the library

activities. This study aims to determine the effectiveness of the NoiseSign in reducing noise levels in an academic library.

\section{Literature Review}

Noise is one of the most common complaints library administrators hear from students. In their survey on cell phone policies in academic libraries, Heaton and Master discovered that 74 percent of respondents considered noise to be a problem at their institutions (Heaton and Master, 2007). Additionally, Yelinek and Bressler observed, "Over the past several years, [the authors] have witnessed a general rise in noise level at their library. This trend was confirmed by comments received during LibQUAL surveys administered at their library [Bloomsburg University of Pennsylvania] in 2006 and 2009. In both surveys, noise was one of the top issues raised by students who sought a quieter place to study"(Yelinek and Bressler, 2013). Franks and Asher (2014) confirm that "University libraries have had to provide acceptable noise levels for many years and this pressure has not diminished in the twentyfirst century." The likely cause is the competing space needs of today's university libraries. As noted in Association of Research Libraries 2014 Spec Kit on library spaces, "Collaboration is at the center of Next-Gen learning spaces, and collaborative spaces come in many forms, not just high-energy activity centered space, but also quiet space for users to reflect, research, and share ideas and information" (Brown et al., 2014). This was discussed similarly in May and Swabey (forthcoming). Survey responses from students at Mount Royal University indicated that students used the library for a variety of purposes, among them social activities as well as academic work. This was echoed in the work of Khoo et al. (forthcoming) who discovered students had a diverse set of space needs for their academic library. Some library users have begun to raise their voices for a return to quiet in the library, including silent floors, reading rooms, and more "traditional" use of library space (Howard, 2012). This request is not from a minority of users: Gardner and Eng (2005) note that the number one reason students visited the undergraduate library at their institution is for quiet study, followed by using computers and group work. Similarly, May and Swabey (forthcoming) found that one of the 
most common responses as to why the library was a good place to study involved noise (or lack thereof): "Many who cited the library as a good place to study alone indicated that it is a quiet place that promotes concentration." In their ethnographic study on graduate student library use at Florida State University, Kinsley et al. (forthcoming) found that 74 percent of respondents indicated they did their best academic work in a quiet environment and that the inability to "control the noise level kept them from using the library." Regalado and Smale (forthcoming) had similar findings in their study at the City University of New York. The authors concluded that noise control was "crucial to consider" and indicated in the title of their article one student's comment that they "are more productive in the library because it's quiet."

Several studies discuss survey results about the prevalence of noise and common strategies academic libraries adopt to combat noise problems (Franks and Asher, 2014; Heaton and Master, 2007; Lever and Katz, 2007). Common noise-reduction strategies include: introducing noise zones, rearranging furniture, soundproofing study areas, monitoring, improving signage, creating noise policies, and adjusting lighting levels (Bell, 2008; Bird and Puglisi, 1984; Clement and Scott, 1994; Crumpton, 2005; Franks and Asher, 2014; Hronek, 1997; Luyben et al., 1981; "Quiet vs. noisy patrons: erecting noisebarriers," 1979; Regalado and Smale, forthcoming; Yelinek and Bressler, 2013)

Of the aforementioned solutions, six have been investigated using evidence-based practices: furniture rearrangement (Luyben et al., 1981), designating spaces and staff monitoring (Bird and Puglisi, 1984), employing guards (Dole, 1990), changing lighting (Hronek, 1997), and introducing policies (Clement and Scott, 1994; Heaton and Master, 2007; Lever and Katz, 2007). Based on these studies, the most effective interventions are furniture rearrangement, staff monitoring, and designating spaces, while adjusting lighting levels, employing guards, and introducing policies produce no measurable effects.

In Luyben et al.'s (1981) study at the State University of New York College at Cortland, the authors broke up sections of upholstered furniture with carrels. They employed both subjective (student perception) and objective (noise readings from a soundmonitoring device) data to determine the efficacy of the intervention. Student perceptions were measured on a Likert scale of 1-10 (1=extremely quiet ; 10=extremely noisy).The researchers discovered that objectively the noise levels did not change (and may in fact have increased in certain instances after the furniture rearrangement). However, following the intervention, students perceived that the noise levels had dropped from 4.38 to 3.90. Additionally, 64 percent of respondents indicated that the area was "very much or somewhat quieter" (Luyben et al., 1981).

Bird and Puglisi (1984) also collected both subjective and objective data in their study at Ohio State University at Mansfield. In this instance, the intervention was the designation of areas of the library as group study rooms as well as increased staff monitoring. Similar to Luyben et al. (1981) objective data were collected via a soundmonitoring device and subjective data were collected via a survey using a 10-point Likertbased scale. Students were asked to rate the general noise level of the library as well as the extent to which they had been annoyed by noise at the library (where 1=extremely quiet/not annoyed and 10=extremely noisy/extremely annoyed). Bird and Puglisi (1984) found that both objectively and subjectively noise decreased following their intervention. There was a 56 percent decline from the initial baseline noise reading following the intervention and the number of students who indicated that the library was "extremely quiet" had risen from 19.7 percent to 58.9 percent following the intervention (Bird and Puglisi, 1984). Similarly, more students rated lower annoyance levels after the intervention 
(45.5 percent pre-intervention to 59.7 percent post-intervention). These results were found to be statistically significant.

Interventions that were less successful or inconclusive included employing guards (Dole, 1990), changing lighting (Hronek, 1997), and introducing policies (Clement and Scott, 1994; Heaton and Master, 2007; Lever and Katz, 2007). In Dole's (1990) study, guards were hired to sit at the library's entrance and collect students' identification cards. The author hypothesized that the presence of guards in their university library would reduce noise despite the fact that the guards were instructed only to collect ID cards at the entrance, not to monitor noise. Dole (1990) employed subjective measurements to gauge the effectiveness of the guards' presence by asking both employees and students about the effect the guards had on library noise levels. Eighty percent of respondents stated that the guards had no effect on noise (Dole, 1990). In another study at Henderson Community College, Hronek (1997) altered lighting levels to ascertain if lower, dimmer lighting led to quieter noise levels in a loud area of the library. The author took sound readings preand post-intervention. She discovered that changing the lighting had no significant effect on noise (Hronek, 1997).

Finally, Heaton and Master (2007) and Lever and Katz (2007) conducted surveys related to cell phone policies in academic libraries. Both articles rely on comments and anecdotal evidence from survey respondents in their conclusions about the effectiveness of such policies and thus are not definitive. For example, Lever and Katz include several comments from survey respondents that state that the policies do not work; however, in their conclusion they write that at their institution, "Enforcing the ringers off policy has quieted the noise level considerably" (Lever and Katz, 2007). Clement and Scott (1994) relied on casual feedback from staff to determine if noise policies and marketing materials they implemented had been effective. Staff reported that they had not found these changes to be effective and that the primary benefit of policies had been to empower staff (Clement and Scott, 1994). They found that staff monitoring aided in reducing noise but that "student cooperation had been harder to achieve in areas with large study tables or where few staff members are visible" (Clement and Scott, 1994). While this article did not employ a scholarly method, it did align with the findings of Bird and Puglisi (1984) that staff monitoring reduces noise.

\section{Aims}

Two hypotheses were tested in this study. The first hypothesis proposed that after the installation of the NoiseSign the levels of noise as perceived by respondents would decrease. The second hypothesis proposed that after the installation of the NoiseSign actual noise levels, as measured by decibal (dB) level measurements, would decrease.

\section{Methods}

We used two types of measurements to determine the effectiveness of the NoiseSign: user surveys of noise levels in the library and actual noise measurements. This methodology was modeled on the work of Luyben et al. (1981) and Bird and Puglisi (1984). Both studies used noise perception in conjunction with noise measurements to determine the effectiveness of their interventions.

Additionally, both Luyben et al. (1981) and Bird and Puglisi (1984) asked users to rate the level of noise in the library using a Likert scale. We adapted this type of question for our study (see Appendix 1 for the survey). Both measurements were taken before and after the installation of the NoiseSign. Additionally, to act as a control for variation in library use during the year, measurements were taken simultaneously in two areas that did not have a NoiseSign installed. 


\section{Survey}

In the present study, a survey was used to determine the respondents' perceived level of noise as well as their desired level of noise. The researchers obtained ethics approval to administer this survey. The survey included two questions and space for additional comments. The two questions were:

1) How would you rate the current level of noise in this study area? (on a scale of $1-10$, where 1 is extremely quiet and 10 is extremely loud)

2) What is your desired level of noise for this study area? (on a scale of 1-10, where 1 is extremely quiet and 10 is extremely loud)

The survey was made available both in print and online, in both the control and intervention areas of each branch.

\section{Noise level measurements}

Decibel $(\mathrm{dB})$ level measurements were taken in order to determine actual noise levels. The app Decibel 10th ${ }^{1}$ (by SkyPaw Co., Ltd.) was installed on iPads and used to record $\mathrm{dB}$ levels. In order to account for variations in library use throughout the week, $\mathrm{dB}$ measurements were taken twice a day, once in the morning (at $\sim 11: 30 \mathrm{am}$ ) and once in the afternoon (at $\sim 4: 30 \mathrm{pm}$ ), for five consecutive days (excluding weekends). Decibel level measurements were only collected twice a day due to limited resources. The times of 11:30 am and 4:30 pm were chosen in order to capture data during high-use periods. All other factors remained consistent. The measurements, which each lasted sixty seconds, were taken in the same location in each area. Headcounts of the number of people using the space at the time of each measurement were also recorded so that any large discrepancies in the number of people would be noted. The inclusion of control areas where the NoiseSign was not installed was intended to compensate for any discrepancies in library usage patterns between the data collection periods (see Appendix 2 for gate counts). For the final phase of the study actual noise measurements were passively collected using the NoiseSign from the intervention areas. These were used to corroborate the manual noise measurements from the Decibel 10th application.

\section{Data Collection}

Data collection occurred over the course of 3 distinct phases:

- Phase 1: Pre-intervention (March $17^{\text {th }}$ to $31^{\text {st }}$ 2014)

- Phase 2: Post-intervention (April $17^{\text {th }}$ to May $2^{\text {nd }}$ 2014)

- Phase 3: Follow-up (November $3^{\text {rd }}$ to $17^{\text {th }}$ 2014)

\section{Phase 1: Pre-intervention}

The first phase of the study took place in early spring and involved measuring the perceived noise levels with a fourteen-day survey period. Additionally, noise (dB level) measurements were taken over five days in each of the four selected areas. Headcounts were taken at the same time as noise measurements to account for any significant difference in usage which might have affected the noise levels. Data collected in this phase was used to act as a baseline for comparison of measurements taken after installation of the NoiseSign.

\section{Phase 2: Post-intervention}

The second phase of the study was delayed by approximately two weeks, due to supplier and installation issues with the NoiseSigns. This phase occurred in later spring and coincided with exam time. A NoiseSign was installed in the intervention area of each branch (see Figures 3 and 5). The methodology for this phase of the study was the same as for the first phase (print and online surveys along with regular $\mathrm{dB}$ level

1 https://itunes.apple.com/ca/app/decibel$\underline{10 \text { th/id448155923? } \mathrm{mt}=8}$ 
measurements and headcounts in both intervention and control areas of each branch). For corroboration the NoiseSigns were set to log dB level data once every minute, twentyfour hours a day.

According to noise-related literature, normal conversation registers at approximately $60 \mathrm{~dB}$ (National Institute on Deafness and Other Communication Disorders, 2011). However, when testing NoiseSign on site, we discovered that it was very sensitive and undiscriminating. For example, we observed that when set to $60 \mathrm{~dB}$, the sign would light up in response to environmental noises such as chairs moving across the floor, coughing, etc. which meant that the light was constantly being activated. Therefore, it was determined that the threshold of the NoiseSign had to be greater than $60 \mathrm{~dB}$. In order to ensure that the threshold was neither too high nor too low it was decided that the NoiseSigns would be programmed to light up at $65 \mathrm{~dB}$.

\section{Phase 3: Follow-up}

The final phase of the study involved collection of data in order to determine the long term effect of the NoiseSigns. In order to replicate library use patterns, data were collected in late fall (seven and a half months after the initial installation of the NoiseSigns), at a time of year with similar gate counts as those of Phases 1 and 2. Due to unforeseen emergency construction in the Schulich Library of Science and Engineering, data were only collected in the Humanities and Social Sciences Library for this final phase. Print and online surveys were collected over a fourteenday period and $\mathrm{dB}$ measurements were collected from the NoiseSign data logging. the Humanities and Social Sciences Library and the Schulich Library of Science and Engineering would be ideal locations for the purposes of this study. Both of these branches are very heavily used-in the fiscal year 2013, the gate count was 4, 366,189 for the Humanities and Social Sciences Library and 494, 867 for the Schulich Library of Science and Engineering.

To determine which specific areas had the biggest noise issues the user survey was first administered in all of the quiet study areas in both of the libraries for fourteen days. In total, 33 areas were surveyed. One of the criteria in determining what was considered an intervention area was that a minimum of 50 percent of the seating needed clear sight lines where the NoiseSign could be installed.

The perceived and desired noise ratings from the collected surveys were subtracted to create a noise differential score. Areas with the highest noise differential score and the most noise related comments were chosen as the intervention areas, as they could benefit the most from the installation of the NoiseSign. The control areas were selected based on their having comparable function, use, and layout to the intervention areas (see Figures 2-5 for the floor plans of each area). One control and one intervention area were designated for each branch.

The inclusion of a control zone was important as student activity varies through the semester and could produce false results (e.g. pre-tests taken during a busy period followed by posttests taken during a low-activity period). Luyben et al. (1981) noted this as a limitation in their study.

\section{Area selection}

The Humanities and Social Sciences Library and the Schulich Library of Science and Engineering are the two largest branches in the McGill University Library system. The number of noise-related comments from the 2013 LibQUAL survey were highest for these two branches; therefore, it was decided that 


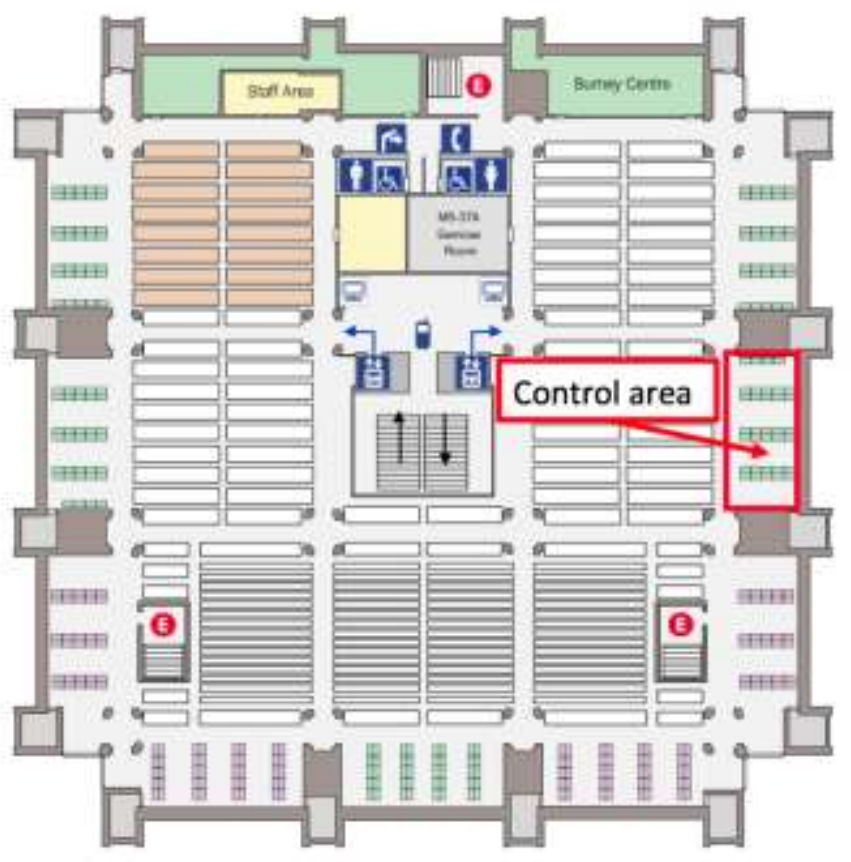

Figure 2: Humanities and Social Sciences Library control area

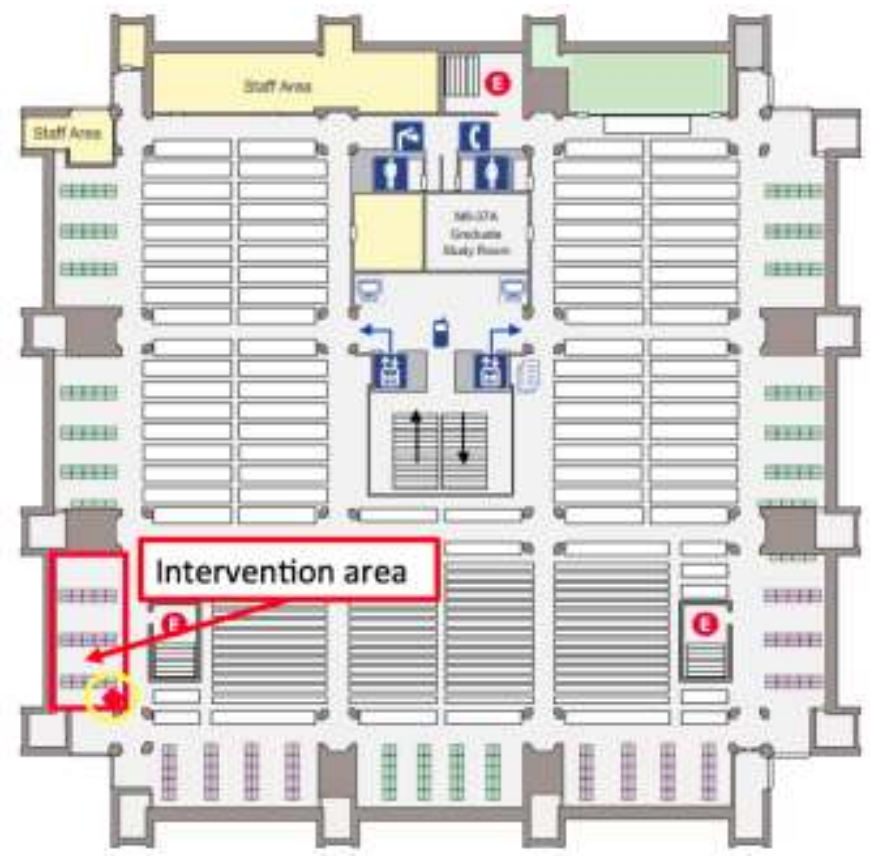

Figure 3: Humanities and Social Sciences Library interventio area (yellow highlighted circle indicates location of NoiseSign

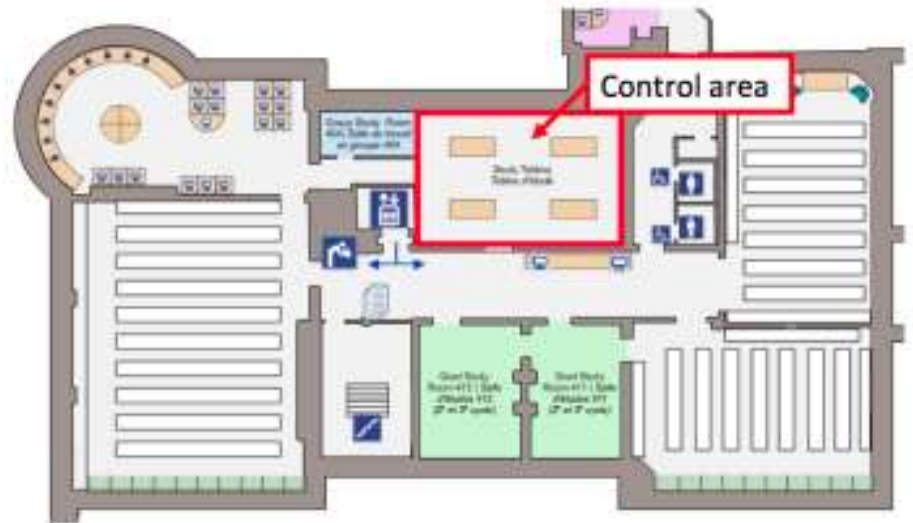

Figure 4: Schulich Library of Science and Engineering control area

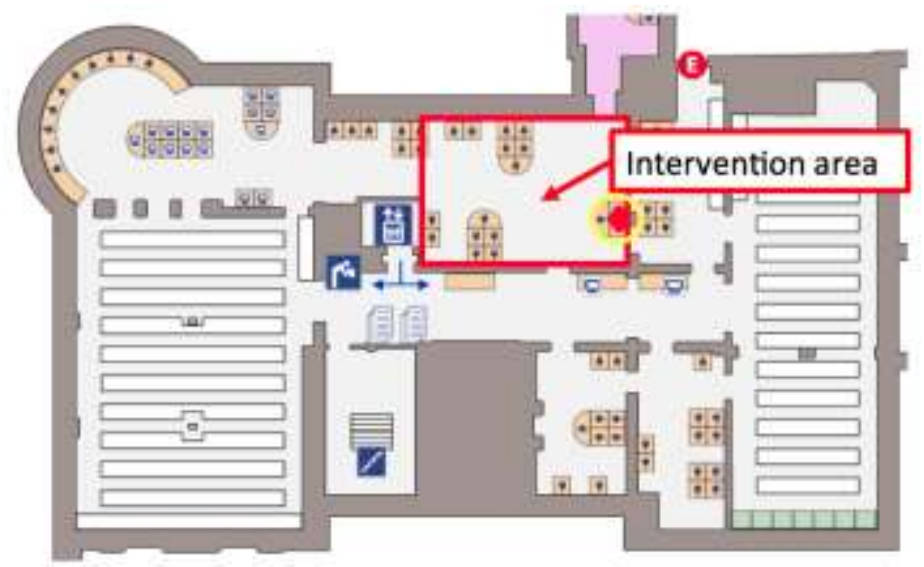

Figure 5: Schulich Library of Science and Engineering intervention area (yellow highlighted circle indicates location of NoiseSign

\section{Results}

\section{Survey responses}

A total of ninety-six surveys were completed and analyzed during the three experimental phases of this study. Not surprisingly, the quantitative analysis of the noise ratings showed that respondents' desired noise levels were largely lower than their perceived noise levels in both the control and intervention areas (See Table 1). 


\begin{tabular}{|c|c|c|c|c|c|}
\hline \multirow{5}{*}{$\begin{array}{l}\text { Humanities } \\
\text { and Social } \\
\text { Sciances } \\
\text { Library }\end{array}$} & & \multicolumn{2}{|c|}{ Control area } & \multicolumn{2}{|c|}{ Intervention erea } \\
\hline & & Perceived & Desired & Perceived & Desired \\
\hline & Pre-intervantion & 2.38 & 2.50 & 3.83 & 1.83 \\
\hline & Post-intervention & 3.50 & 1.75 & 5.80 & 220 \\
\hline & Follow-up & 4.00 & 2.33 & 3.20 & 1.60 \\
\hline \multirow[b]{2}{*}{$\begin{array}{l}\text { Schulich } \\
\text { Lbrary of } \\
\text { Sciance } \\
\text { and } \\
\text { Enginearing }\end{array}$} & Pro-intervention & 3.70 & 2.20 & 4.09 & 2.14 \\
\hline & Post-intervention & 3.93 & 1.79 & 3.71 & 1.71 \\
\hline
\end{tabular}

Table 1 - Mean perceived noise and desired noise levels as indicated in survey responses on a scale of 1 to 10 (1=extremely quiet, $10=$ extremely loud).

A one-way ANOVA was conducted to compare the effect of the installation of the NoiseSign on the survey respondents' perception of noise, both in the short and long term (Phases 2 and 3), in the control and intervention areas of the Humanities and Social Sciences Library. The installation of the NoiseSign did not have a significant effect on survey respondents' perception of noise in either area $[F(5,25)=2.45, p>0.05]$. These results suggest that the NoiseSign did not have either a short-term or long-term effect on users' perception of noise levels in the Humanities and Social Sciences Library (see Figure 7) and thus, the null hypothesis was not rejected.

These findings were in contrast to Luyben et al.'s (1981) as well as Bird and Puglisi's (1984) research that found subjective ratings of noise significantly decreased following their interventions.

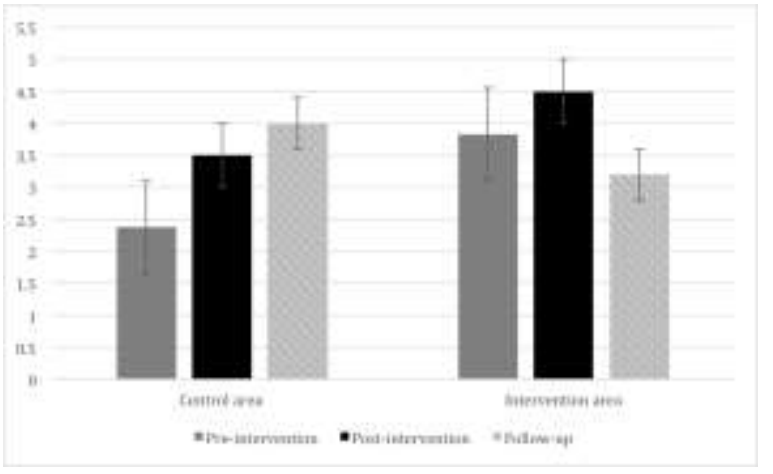

Figure 6-Mean perceived noise levels in Humanities and Social Sciences Library Phases 1, 2 and 3 as indicated in survey responses on a scale of 1 to 10 (1=extremely quiet, $10=$ extremely loud)

Similarly, a one-way ANOVA was conducted to compare the effect of the installation of the NoiseSign on the survey respondents' perception of noise in the short term (Phase 2) in the control and intervention areas of Schulich Library of Science and Engineering. As explained above, unforeseen circumstances prevented data collection for the third experimental phase (long-term effect) in the Schulich Library of Science and Engineering. The NoiseSign did not have a significant effect on survey respondents' perception of noise levels in either area $[\mathrm{F}(3$, $58)=0.115, p>0.05]$. These results suggest that the NoiseSign did not have a short-term effect on users' perception of noise levels in the Schulich Library of Science and Engineering (see Figure 7) and thus, the null hypothesis was not rejected.

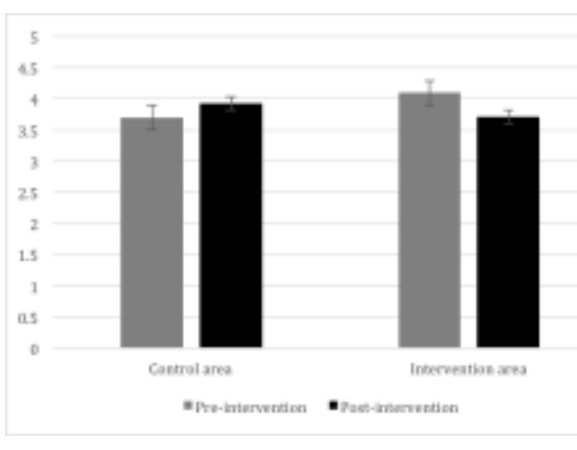

Figure 7-Mean perceived noise levels in Schulich Library of Science and Engineering Phases 1 and 2 as indicated in survey responses on a scale of 1 to 10 (1=extremely quiet, $10=$ extremely loud)

\section{Survey comments}

The comments response rate was high at over 75 percent and qualitative analysis of the survey comments brought out a number of themes:

\section{Types of noise}

High number of survey responses included detailed comments on what kinds of noises respondents were hearing in the area. For example: "Some people chew too loud when they eat. Some people talk on the phone between the book cases. They should move next to the elevators" and "chomping food noise, slurping slushies, crunching chips." As expected student talking was also identified as a leading cause of disruption. For example, "I find it difficult to study here during prime visiting hours (Approx. 10:45am to 18:30 because people often 'whisper', chat across 
study booths and play music that is audible through their headphones. I don't study here without my ear plugs to block out this noise." and "People in the library are typically too loud. People who wear headphones are often oblivious to the noise that they make. Too much talking."

\section{Origin of the noise}

Based on the comments received, observation, and anecdotal information, the origin of the most disruptive sound was not from people themselves using quiet areas, but rather from areas adjacent to quiet study zones.

Nearby hallways and group study rooms were most commonly mentioned as sources of noise: "people talking in the hallways, whispering loudly in study rooms, chewing, crunching, phone chirping and vibrating...makes it hard to focus"; "students talk loudly in hallways (near printers) and don't realize their voices carry through the floor"; "the group study room is NOT soundproof. It should either be made so, or have a sign to remind people of that."

Noise from the outside the library building was also mentioned: "They [sic] only perceived noise comes from the outside"; "The only noise that I can hear is from the cars outside"; "Who decides they should play live music in the quad when people still have finals."

Library staff were also identified as a source of noise: "the only people who are loud are the staff of the library" and "People in their offices might want to be aware that we can hear everything they're saying pretty clearly."

Occasionally, when the perceived noise levels became intolerable, some survey respondents comment that they resort to self-monitoring: "people whisper, but it's very loud. I tell them to stop sometimes, but after a while it continues."
Several students left comments requesting additional types of noise spaces in the library. For example: 'So many new 'study zones' that cater to group work have been created, but there has been no equivalent expansion of quiet study zones. While some disciplines may promote group learning, the humanities does not; individual thought is valued. As a humanities library, there should be more quiet spaces for students to read and reflect." One student's solution to noise in quiet study spaces was to request that the library provide additional study spaces that were technology free: "Please, please, please.... Dedicate part of the library as a reading / studying area where technology is NOT allowed!" Other students requested that noisier spaces be permitted: "provide library space (for example, the third floor) where some talking is permitted." This likely reflects the different user needs for their library spaces but interestingly, some survey comments indicate that some noise is conducive to studying; "it's depressing when totally silent," "I like ambient noise", and "it's too quiet and intense. Much easier to study in a more laid back environment."

\section{Noise measurements}

As described above, $\mathrm{dB}$ measurements and headcounts were taken in Phases 1 and 2 of the study. The mean dB levels recorded by these measurements indicate that noise levels varied within a $4 \mathrm{~dB}$ range (see Table 3 ). Additionally, there was very little variation in the mean number of people using the study space during the morning and afternoon measurement in either branch (see Table 2).

\begin{tabular}{|c|c|c|c|c|c|}
\hline \multirow{4}{*}{$\begin{array}{l}\text { Humarites } \\
\text { and Social } \\
\text { Sciences } \\
\text { Library }\end{array}$} & & \multicolumn{2}{|c|}{ Control area } & \multicolumn{2}{|c|}{ Intervention area } \\
\hline & & Morning & Altemoon & Morning & Aflemoon \\
\hline & $\begin{array}{l}\text { Phase } 1 \text {-Pre- } \\
\text { interyention }\end{array}$ & 46.54 (11) & $47.00(10)$ & $48.88(11)$ & $46.81(8)$ \\
\hline & $\begin{array}{l}\text { Phase 2-Post- } \\
\text { intervention }\end{array}$ & 47.B1 (11) & $48.18(12)$ & $49,49(13)$ & $48.97(12)$ \\
\hline \multirow{2}{*}{$\begin{array}{l}\text { Schulich } \\
\text { Library of } \\
\text { Science } \\
\text { and } \\
\text { Engineering }\end{array}$} & $\begin{array}{l}\text { Phase } 1 \text {-Pre- } \\
\text { intervention }\end{array}$ & $48.87(6)$ & $48.02(11)$ & $48.88(13)$ & $47.65(20)$ \\
\hline & $\begin{array}{l}\text { Phase 2. Post- } \\
\text { intervention }\end{array}$ & $45,62(12)$ & 46.79 (11) & $45.49(16)$ & $46.19(19)$ \\
\hline
\end{tabular}

Table 2-Mean dB level readings in each branch and area, (mean number of people using the space as determined by headcounts at the time of measurement indicated in parentheses) 
One-way ANOVAs were conducted to compare the effect of the NoiseSign on $\mathrm{dB}$ levels in the control and intervention areas during Phases 1 and 2 of the study for each branch. The $\mathrm{dB}$ levels in either area of the Humanities and Social Sciences Library did not significantly change between Phase 1 and 2 $[F(3,36)=1.25, p>0.05]$. Similarly $d B$ levels in either area of the Schulich Library of Science and Engineering did not significantly change between Phase 1 and $2[F(3,37)=2.74$, $p>0.05]$. These results suggest that the installation of the NoiseSign did not affect $\mathrm{dB}$ levels in the intervention area of either branch and thus, the null hypothesis was not rejected

\section{Data logging}

Measurements taken from the data logging feature of the NoiseSign confirm the results of the $\mathrm{dB}$ measurements. Specifically, the majority of $\mathrm{dB}$ measurements fell within a small range $(45-50 \mathrm{~dB})$ and very rarely exceeded the $65 \mathrm{~dB}$ threshold of the NoiseSign (it should be noted that $\mathrm{dB}$ is a logarithmic scale, rather than a linear scale). Plotting data from the NoiseSign dB logging show clear trends in daily and weekly noise levels (see Figure 8).

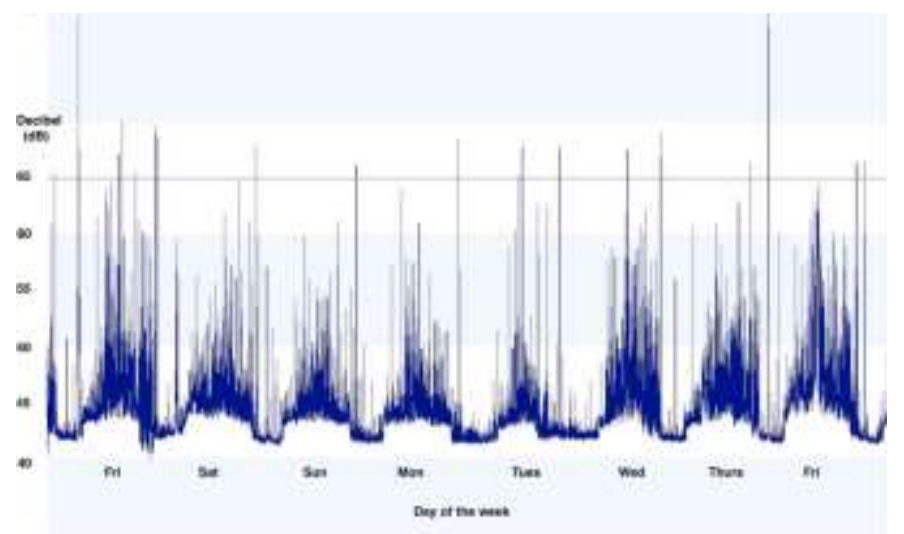

Figure 8-Fluctuations in $\mathrm{dB}$ levels ( $\mathrm{dB}$ readings taken every minute, 24 hours a day) over the course of one week. Green line represents where the trigger was set for the sign to go off at 65 $\mathrm{db}$.

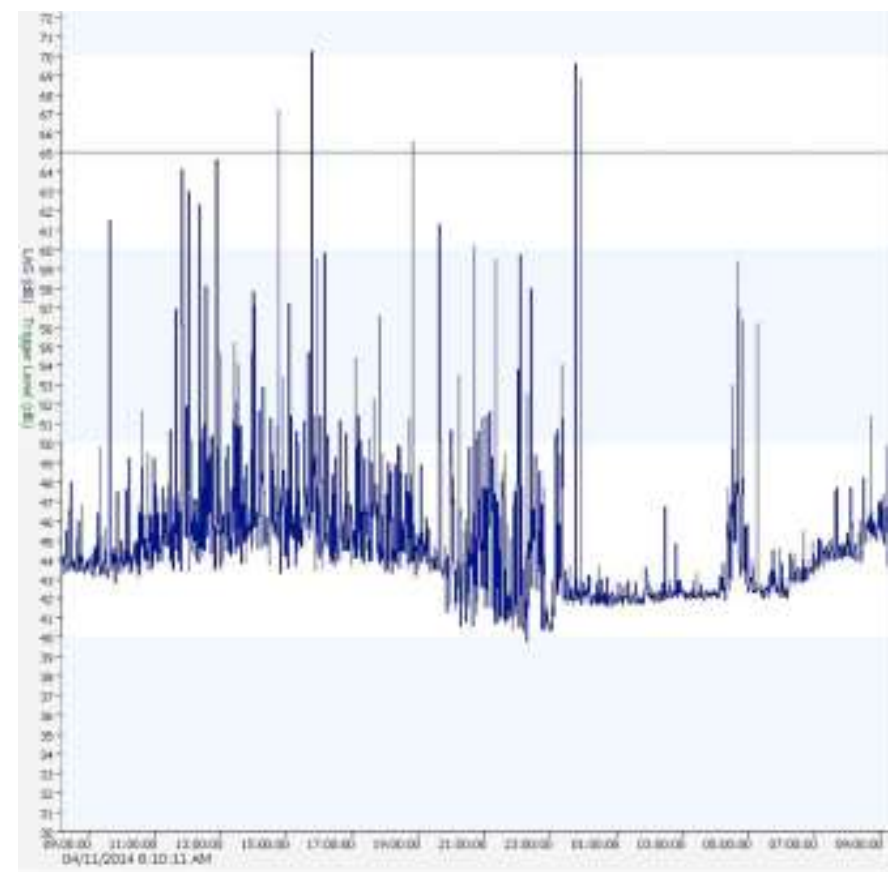

Figure 9 - Fluctuations in $\mathrm{dB}$ levels over an average week day. $\mathrm{dB}$ readings taken every minute, 24 hours a day. Green line represents where the trigger was set for the sign to go off at 65 $\mathrm{db}$.

\section{Discussion}

The purpose of this study was to determine the effectiveness of the NoiseSign on reducing noise levels in an academic library setting. It was hypothesized that the visual feedback provided by the NoiseSign would encourage library users to reduce their noise levels, thereby influencing both actual noise levels, as well as users' perception of noise levels. However, data analysis indicates that the actual noise levels, as determined by $\mathrm{dB}$ level measurements, did not decrease after the installation of the NoiseSign. Similarly, survey respondents' perception of noise levels did not significantly change after the installation of the NoiseSign.

Our initial premise that the NoiseSign would provide analogous visual feedback to speed monitoring devices, and thus similar positive results, required renewed consideration in light of the results of the current study. We propose several possibilities for why the NoiseSign was 
not effective for reducing noise levels in the way that speed-monitoring signs are effective in reducing speed. Firstly, speed limits are easily quantified whereas noise levels are subjective. As such, each individual has different perceptions of what they consider "acceptable" noise levels in any given situation. Secondly, actively monitoring speeds (via speedometers, signage, etc.) is very common, whereas actively monitoring noise levels is quite rare. Thirdly, it is possible that the student(s) making noise either may not notice the activated NoiseSign, or may not realize that the sign was activated as a result of their behavior. As such, the activation of the NoiseSign may not always result in changes in behavior and a subsequent reduction of noise. Finally, without supporting policy and enforcement (which we did not have in the current study), there are no significant consequences for making noise in a quiet study area. As such, some people will be less motivated to maintain a quiet space.

Furthermore, the decibel level measurements reveal that quiet study areas within the library are in fact quiet and noise levels often stay within the 45-50dB range (see Figure 8 and 9). Survey comments revealed that offending noise coming from students in the quiet areas was of such low decibel levels that they would not have been picked up by the NoiseSign (e.g. unwrapping candy, keyboard tapping, whispering etc.). This further limited the effectiveness of the sign in the current study.

We had also incorrectly assumed that most of the offending noise was coming from students within the quiet study areas (as the areas are relatively well-isolated). Comments received from the surveys confirm this. Students reported in the comments that sources of noise most often originated from areas adjacent to quiet study areas. One student wrote: "quite easy for sound to carry across the whole floor. it [sic] people studying 'outside' the study area cause the most disruption" and likewise "students talk loudly in hallways (near printers) and don't realize their voices carry through the floor". This was not anticipated and likely greatly reduced the efficacy of the NoiseSign further as the sign provides feedback only in its immediate surroundings. Since the source of the noise was often coming from adjacent areas, the NoiseSign was an ineffective tool in these instances.

Interestingly, the number of people using the space did not have any effect on actual noise levels, as determined by $\mathrm{dB}$ measurements (see Table 1). About half of the time, higher $\mathrm{dB}$ levels corresponded with more people using the space. However, the other half of the time the $\mathrm{dB}$ levels were slightly lower at times when more people were using the space. Although these results are not statistically significant, it is possible that students are more likely to selfmonitor when there are more people around them. Although we noted in the introduction that relying on student self-monitoring is an unreliable way to manage noise concerns, it is an intriguing phenomenon that warrants further attention.

Although the NoiseSign produced no noticeable effects on student perception of noise, students were aware of the sign. Students at the university maintain a page on a social media site related to things they observe in the library. Posts are often funny or express frustrations related to some aspect of the library buildings. A post about the NoiseSign appeared on this page in November 2014. Comments related to the post expressed dismay that the Library would spend money on NoiseSign devices as opposed to other services or resources, especially in a time of shrinking budgets.

\section{Limitations and future research}

There are a number of limitations in this study that could be addressed in future research. Firstly, in the Schulich Library of Science and Engineering it was difficult to find two areas to use for control and intervention with similar layout, function and use. Specifically, the control area was smaller (seating for sixteen people), the tables were not wired and there was a group study room nearby; whereas the intervention area was 
bigger (seating for twenty-seven people), had wired tables and was not located near a group study room. As a result, the chosen control and intervention areas were not ideally comparable. This was not an issue in the Humanities and Social Sciences Library because the layout and arrangements of each floor in the Humanities and Social Sciences Library are very similar. In future research, to the greatest extent possible, the control and intervention areas should be comparable in terms of layout, function and use.

Secondly, as described above, the second phase of the study was delayed due to issues related to the installation of the NoiseSign. As such, data collection for this phase coincided with exam time. This proved not to have any effect on dB levels or users' perception of noise, since statistical analysis showed no significant difference in either measurement, pre- and post-NoiseSign installation. However, there was a decrease in survey responses between the first and second phases of the study, which could be accounted for by the timing of the second phase.

Alternatively, the decrease in response rate might be explained by library users experiencing survey fatigue.

Before beginning Phase 2 of the study, the NoiseSign was tested in a quiet study area. The sensitivity of the NoiseSign required that we program it to light up at $65 \mathrm{~dB}$, a level of noise rarely reached in the environment. In future research it would be interesting to see if the NoiseSign had any effect if programmed to respond at a lower decibel level ( 50dB).

\section{Conclusion}

Although previous research had suggested that a monitoring presence would reduce noise levels, the NoiseSign unfortunately did not produce such an effect. It is unclear if modifying the NoiseSign would provide better results. The sign could be improved for an academic library environment-for example, the researchers propose that a modified NoiseSign (one that illuminates only after five seconds of continuous noise) would be more useful in this setting. This would permit libraries to set the noise threshold lower but not have the sign illuminate with every chair scratch or cough. However, that alone would not address the larger factors that possibly limited its efficacy: lack of individual feedback, no "known" acceptable decibel levels and lack of consequences for activating the sign. While some of the issues discussed could potentially be addressed, they would be at a greater financial cost (e.g. modifying the NoiseSign as described above, posting more devices, etc.). Additionally, we discovered that in our particular setting, the majority of noise was coming from outside the NoiseSign area. The NoiseSign would perhaps be more effective in spaces where noise is permitted but library administrators would still seek to keep the volume at a defined level (e.g. hallways adjacent to quiet study areas). This would perhaps be a better use of the sign: not to keep quiet areas quiet, but to keep nearby social areas from becoming too loud.

In spite of the rejection of our hypotheses, information gathered from user surveys provided important insights into noise at our institution. For example, we learned that the source of noise was not necessarily from other students in the quiet study space, but from adjacent areas such as stairwells, hallways, group study rooms etc. Some small improvements, such as ensuring doors/entryways to quiet areas remain closed, clearer delineation of study versus group zones, and a review of the libraries' noise policies have been undertaken to try to account for these issues. Additionally, data logging from the NoiseSign demonstrated that our quiet spaces were in fact relatively quiet most of the time (as the readings were in the $45-50 \mathrm{db}$ range) but that this level of quiet was not what was desired by students (as indicated by the surveys). Another interesting observation was that half of the time sound levels (as measured using the decibel reader) decreased with the presence of more students. 
It has been suggested in the literature that student self-monitoring reduces noise. This preliminary data suggest more research should be undertaken in this area to determine the extent to which that suggestion may be true.

Given the importance of library spaces for today's students and the diverse needs of our user populations, noise is likely to continue to be an issue for academic libraries. Although many solutions have been proposed there have been few studies that have looked at these solutions rigorously. Future directions in this research would potentially look at other monitoring options. For example, would security guards who actively monitor noise have an effect? To what extent is student selfmonitoring effective? Is it possible to adapt a device like the NoiseSign to be more suitable to a library environment? Rather than relying on monitoring and feedback, perhaps furniture rearrangement and space design would produce better results? Although there are some studies on which to base noise solution decisions, more work is needed to provide the quiet spaces today's students desire. It is our hope that this article will help library administrators and space planners choose effective noise-reduction strategies. 


\section{References}

Bedwell, L. and Banks, C.S. (2013), "Seeing through the eyes of students: Participant observation in an academic library", Partnership: the Canadian Journal of Library and Information Practice and Research, Vol. 8. No. 1, available at:

https://journal.lib.uoguelph.ca/index.php/perj/article/view/2502\#.VRc-Cmbfg14 (accessed 26 March 2015).

Bell, S. (2008), "Stop having fun and start being quiet: Noise management in the academic library", Library Issues, Vol. 28 No.4 pp.1-4.

Bird, C.P. and Puglisi, D.D. (1984), "Noise reduction in an undergraduate library", Journal of Academic Librarianship, Vol. 10 No. 5, pp. 272-277.

Bloch, S. (1998), "Comparative study of speed reduction effects of photo-radar and speed display boards", Transportation Research Record: Journal of the Transportation Research Board, Vol. 1640, pp. 27-36.

Brown, S., Bennett, C., Henson, B. and Valk, A. (2014), SPEC Kit 342: Next-Gen Learning Spaces, Association of Research Libraries, Washington, DC.

Clement, E. and Scott, P.A. (1994), "No food, no drink, no noise", College and Research Libraries News, Vol. 55 No.2, p. 81.

Crumpton, M.A. (2005), "Sounding off about noise", Community \& Junior College Libraries, Vol. 13 No.4, pp. 93-103.

Dole, W.V. (1990), "The effectiveness of guards in reducing library noise", Library \& Archival Security, Vol. 9 No.3-4, pp. 23-36.

Foster, N.F. and Gibbons, S. (2007), Studying Students: the Undergraduate Research Project at the University of Rochester, Association of College and Research Libraries, Chicago, IL.

Franks, J.E. and Asher, D.C. (2014), "Noise management in twenty-first Century libraries: Case studies of four U.S. academic institutions", New Review of Academic Librarianship, Vol. 20 No.3, pp. 320-331.

Gardner, S. \& Eng, S. (2005), What students want: Generation Y and the changing function of the academic library. portal: Libraries and the Academy, Vol. 5 No.3, pp. 405-420.

Gehlert, T., Schulze, C. and Schlag, B. (2012), "Evaluation of different types of dynamic speed display signs", Transportation Research Part F, Vol. 15 No. 6, pp. 667-675.

Heaton, S. and Master, N. (2007),"No phone zone", Public Services Quarterly, Vol. 2 No.4, pp. 6980.

Howard, J. (2012), "At libraries, quiet makes a comeback", The Chronicle of Higher Education, available at: http://chronicle.com/article/At-Libraries-Quiet-Makes-a/132885/ (accessed 26 March 2015).

Hronek, B. (1997), "Using lighting levels to control sound levels in a college library", College \& Undergraduate Libraries, Vol.4 No.2, pp. 25-28.

Kinsley, K., Besara, R., Scheel, A., Colvin, G., Evans Brady, J. and Burel, M.(forthcoming), "Graduate conversations: Assessing the space needs of graduate students", College \& Research Libraries, available at: http://crl.acrl.org/content/early/2014/11/26/crl14-694.full.pdf+html (accessed 15 August 2015)

Khoo, M.J., Rozaklis, L., Hall, C. and Kusunoki, D. (forthcoming), "A really nice spot”: Evaluating place, space, and technology in academic libraries", College \& Research Libraries, available at: http://crl.acrl.org/content/early/2015/04/10/crl15-698.full.pdf+html (accessed 15 August 2015)

Lever, K.M. and Katz, J.E. (2007), "Cell phones in campus libraries: An analysis of policy responses to an invasive mobile technology", Information Processing \& Management, Vol.43 No. 4, pp. 1133-1139.

Luyben, P.D., Cohen, L., Conger, R. and Gration, S.U. (1981), "Reducing noise in a college library", College \& Research Libraries, Vol. 42 No. 5 pp. 470-481. 
May, F. and Swabey, A. (forthcoming), "Using and experiencing the academic library: A multi-site observational study of space and place", College \& Research Libraries, available at: http://crl.acrl.org/content/early/2015/03/10/crl14-683.full.pdf+html (accessed 15 August 2015)

National Institute on Deafness and Other Communication Disorders. (2011), "How loud is too loud", available at: http://www.nidcd.nih.gov/health/hearing/pages/ruler.aspx (accessed 26 March 2015).

"Quiet vs. noisy patrons: Erecting noise barriers", (1979), Library Journal, Vol.104, p.145.

Regalado, M. and Smale, M.A. (forthcoming), "I am more productive in the library because it's quiet:" Commuter students in the college library", College \& Research Libraries, available at: http://crl.acrl.org/content/early/2015/02/05/crl14-696.full.pdf+html (accessed 15 August 2015)

Santiago-Chaparro, K.R., Chitturi, M., Bill, A., and Noyce, D.A. (2012), "Spatial effectiveness of speed feedback signs", Transportation Research Record: Journal of Transportation Research Board, Vol. 2281, pp. 8-15.

Yelinek, K. and Bressler, D. (2013), "The perfect storm: A review of the literature on increased noise levels in academic libraries", College \& Undergraduate Libraries, Vol. 20 No. 1, pp. 40-51. 


\section{Appendix 1}

\section{Survey - Noise in the library - Humanities and Social Sciences Library}

3rd-floor Zone

The survey you submit will be used as part of a research study on noise in the library. Your participation in this survey is completely voluntary and anonymous. The participant cannot withdraw from the study once the survey responses have been submitted. Please do not write your name or any other identifying information. The result of this study might be used in presentations at conferences, publications, and in internal staff reports/presentations.

Date:

Time:

How would your rate the current level of noise in this study area?

$1=$ extremely quiet to $10=$ extremely loud

$\begin{array}{llllllllll}1 & 2 & 3 & 4 & 5 & 6 & 7 & 8 & 9 & 10\end{array}$

What is your desired level of noise for this study area?

$1=$ extremely quiet to $10=$ extremely loud

$\begin{array}{llllllllll}1 & 2 & 3 & 4 & 5 & 6 & 7 & 8 & 9 & 10\end{array}$

\section{Additional comments}

If you have any questions regarding this study, please contact $X$. If you have any questions or concerns regarding your rights or welfare as a participant in this research study, please contact XX. 


\section{Appendix 2}

Gate Counts per branch during three phases of data collection

\begin{tabular}{|l|c|c|c|}
\hline & $\begin{array}{c}\text { Phase 1: } \\
\text { Pre- } \\
\text { intervention } \\
\text { (March 17-31, } \\
\text { 2014) }\end{array}$ & $\begin{array}{c}\text { Phase 2: } \\
\text { Post-intervention } \\
\text { (April 17 to May 2, } \\
\text { 2014) }\end{array}$ & $\begin{array}{c}\text { Phase 3: } \\
\text { Follow-up } \\
\text { (November 3 to } \\
\text { November 17, } \\
\text { 2014) }\end{array}$ \\
\hline $\begin{array}{l}\text { Humanities } \\
\text { and Social } \\
\begin{array}{l}\text { Sciences } \\
\text { Library }\end{array}\end{array}$ & 154949 & 142156 & 172139 \\
\hline $\begin{array}{l}\text { Schulich } \\
\text { Library of } \\
\text { Science } \\
\text { and } \\
\text { Engineering }\end{array}$ & 29223 & 20643 & \\
\hline
\end{tabular}

